\title{
Mechanical nociceptive assessment of the equine hoof following distal interphalangeal joint intra-articular anesthesia
}

\author{
Bruno D Malacarne ${ }^{1}$, Leticia O Cota ${ }^{1}$, Antônio C P Neto ${ }^{1}$, Cahuê F R Paz ${ }^{2}$, Lucas A Dias ${ }^{1}$, Mayara G Corrêa ${ }^{1}$, \\ Armando M Carvalho ${ }^{\text {Corresp., } 1}$, Rafael R Faleiros ${ }^{1}$, Andressa B S Xavier ${ }^{1}$ \\ ${ }^{1}$ Department of Veterinary Clinics and Surgery- Equinova Research Group, School of Veterinary, Universidade Federal de Minas Gerais, Belo Horizonte, \\ Minas Gerais, Brazil \\ ${ }^{2}$ Centro Universitário INTA-Uninta, Sobral, Ceará, Brazil \\ Corresponding Author: Armando M Carvalho \\ Email address: armandodvm@gmail.com
}

Background: With the hypothesis that equine dorsal lamellar tissue can be desensitized by anesthesia injection into distal interphalangeal joint (DIPJ), the objective was to assess the mechanical nociceptive threshold of hoof dorsal lamellae following intra-articular (IA) administration of lidocaine into this joint. Methods: The DIPJ of the forelimbs of six adult healthy horses were injected with either $5 \mathrm{~mL}$ of lidocaine, or $5 \mathrm{~mL}$ of lactated ringers solution. Treatments were randomly distributed, with each forelimb undergoing a single treatment. The hooves were evaluated pre- and post-injection at pre-selected times over 4 hours, using a pressure algometry model. Mechanical nociceptive thresholds (MNTs) were recorded for the sole (dorsal, palmarolateral, and palmaromedial regions), coronary band (medial, lateral, and dorsal regions), heel bulbs (medial and lateral), and dorsal lamellar region ( $2 \mathrm{~cm}$ and $4 \mathrm{~cm}$ distal to the coronary band). The MNT means were compared over time using the Friedman test and between treatments using the Wilcoxon signed-rank test, with values of $P<0.05$ considered statistically significant. Results: There were no differences between treatments for any region of the hoof during the evaluation period. However, MNT values indicating analgesia were recorded in the dorsal lamellar region in $50 \%$ of hooves following adminstration of lidocaine into the DIPJ. Conclusion: The administration of $5 \mathrm{~mL}$ of lidocaine into the DIPJ does not significantly increase the mechanical nociceptive threshold of the equine hoof. 


\author{
1 Mechanical nociceptive assessment of the equine hoof \\ 2 following distal interphalangeal joint intra-articular \\ 3 anesthesia \\ 5 \\ Bruno Dondoni Malacarne ${ }^{1}$, Leticia Oliveira Cota ${ }^{1}$, Antônio Catunda Pinho Neto ${ }^{1}$, Cahuê \\ Francisco Rosa Paz ${ }^{2}$, Lucas Antunes Dias ${ }^{1}$, Mayara Gomes Corrêa ${ }^{1}$, Armando de Mattos \\ Carvalho $^{1}$, Rafael Resende Faleiros ${ }^{1}$, Andresa Batista Silveira Xavier ${ }^{1}$ \\ 1 Department of Veterinary Clinics and Surgery- Equinova Research Group, School of \\ Veterinary, Universidade Federal de Minas Gerais, Belo Horizonte, MG, Brazil \\ 2 Centro Universitário INTA-Uninta. Sobral-CE, Brazil \\ Corresponding Author: \\ Armando de Mattos Carvalho ${ }^{1}$ \\ Avenida Antônio Carlos 6627, Belo Horizonte, Minas Gerais, 31270-901, Brazil \\ 21 \\ Email address: armandodvm@gmail.com
}




\section{Abstract}

24 Background: With the hypothesis that equine dorsal lamellar tissue can be desensitized by anesthesia injection into distal interphalangeal joint (DIPJ), the objective was to assess the mechanical nociceptive threshold of hoof dorsal lamellae following intra-articular (IA) administration of lidocaine into this joint.

Methods: The DIPJ of the forelimbs of six adult healthy horses were injected with either $5 \mathrm{~mL}$ of lidocaine, or $5 \mathrm{~mL}$ of lactated ringers solution. Treatments were randomly distributed, with each forelimb undergoing a single treatment. The hooves were evaluated pre- and post-injection at pre-selected times over 4 hours, using a pressure algometry model. Mechanical nociceptive thresholds (MNTs) were recorded for the sole (dorsal, palmarolateral, and palmaromedial regions), coronary band (medial, lateral, and dorsal regions), heel bulbs (medial and lateral), and dorsal lamellar region ( $2 \mathrm{~cm}$ and $4 \mathrm{~cm}$ distal to the coronary band). The MNT means were compared over time using the Friedman test and between treatments using the Wilcoxon signedrank test, with values of $P<0.05$ considered statistically significant.

Results: There were no differences between treatments for any region of the hoof during the evaluation period. However, MNT values indicating analgesia were recorded in the dorsal lamellar region in 50\% of hooves following adminstration of lidocaine into the DIPJ.

Conclusion: The administration of $5 \mathrm{~mL}$ of lidocaine into the DIPJ does not significantly increase the mechanical nociceptive threshold of the equine hoof. 
47

\section{Introduction}

To date, diagnostic anesthesia remains the best method for localization of lameness pain in horses, although misinterpretation due unspecific analgesia may occur (Schumacher \& Schramme, 2018). The lack of specificity of the distal interphalangeal joint (DIPJ) anesthetic block is still a focus of discussion, due to evidences of local drug diffusion into periarticular tissues such the navicular bursa (Gough et al 2002) and the navicular bone (Keegan et al 1996). Anesthetics injected into the DIPJ are thought to diffuse through tissues in defined sequences; therefore, frequent evaluations post-injection are considered important for determining if the correct anatomical location has been affected (Bowker, 2007). Evaluation and interpretation of the analgesic effect on the DIPJ or navicular bursa should occur approximately 5 to 10 minutes post-injection (Schumacher et al., 2013). Reportedly, intra-articular (IA) administration of mepivacaine into the DIPJ desensitizes the DIPJ (Easter et al., 2000), navicular bursa (Pleasant et al., 1997; Gough, Mayhew \& Munroe, 2002), navicular bone (Dyson \& kidd, 1993), collateral ligaments of the navicular bone (Bowker, 1997), dorsal and palmar sole region, depending on the volume of mepivacaine administered (Schumacher et al., 2000; 2001), and distal portion of the deep digital flexor tendon (DDFT) (Dyson et al., 2003). With the hypothesis that the dorsal lamellar tissue of the equine hoof can be desensitized by local anesthesia of the DIPJ, the objective of this study was to use pressure algometry to evaluate the mechanical nociceptive threshold (MNT) in pre-selected regions of the equine hoof following IA administration of $5 \mathrm{~mL}$ of $2 \%$ lidocaine into the DIPJ.

Animals and experimental design 

randomized blocks and repeated measurements over time design. The horses were 7-13 years of age (median, 9 years), 142-164 cm tall (median, $146 \mathrm{~cm}$ ), and weighed 350-460 kg (median, $355 \mathrm{~kg}$ ). All horses were considered clinically healthy, determined via physical and orthopedic examination. A complete lameness examination was also performed on all horses to assure that no lameness was present prior to beginning the study (Kaneps, 2014).

\section{Hoof preparation}

Prior to the start of the study, horses were restrained in stocks, and their hooves were performed as previously described by Paz et al. (2016). Horses were sedated with detomidine (20 $\mu \mathrm{gg}^{-1}$ intravenous (IV); Detomidin, Sintec) followed by intramuscular (IM) administration of tetanus antiserum (5000 IU; Lema Injex) and asepetic preparation of the hoof capsule. Two hoof wall defects were made in the center of the dorsal hoof wall of each fore foot, using a $10 \mathrm{~mm}$ drill bit mounted onto a drill (Dewalt 12v max). The first defect was located $2 \mathrm{~cm}$ distal to the coronary band and the second $4 \mathrm{~cm}$ distal to the coronary band. Hoof wall defects penetrated only the insensitive horn, stopping immediately before reaching the sensitive lamellae. Using a

87 hoof knife, the sole of each hoof was prepared by removing the keratinized layer until reaching the sensitive tissue near the solar corium at three different points close to the palmarolateral, palmaromedial, and dorsal borders of the sole (Fig. 1). 
91

92

93

94

95

96

97

98

Injection of the DIPJ

Injections into the DIPJs were performed 24 hours following preparation of the hooves and in complete absence of any sedative effects. Treatments were randomized in each horse, with one DIPJ receiving $5 \mathrm{~mL}$ of 2\% lidocaine (Xylestesin 2\%, Laboratory Cristália Pharmaceuticals Ltd) and the other DIPJ receiving $5 \mathrm{~mL}$ of lactated ringers solution (Samtec Biotechnology). The horses were restrained in stocks, and a nose twitch was applied. Complete aseptic preparation of the the injection site was performed prior to administering the treatment into each forelimb. A dorsolateral DIPJ injection technique was used, as previously described (Moyer, Schumacher \& Schumacher, 2011). The presence of synovial fluid in the hub of the needle and the absence of resistance during injection confirmed access into the joint. Either lactated ringers solution or 2\% lidocaine was administered through a $30 \mathrm{~mm} \times 0.8 \mathrm{~mm}$ needle and $5 \mathrm{~mL}$ syringe.

\section{Algometry}

Pressure algometry was utilized to evaluate the MNT for each hoof. A portable dynamometer (Instrutemp 20kgf ITFG-5020), calibrated by the manufacturer for compression, was used to determined the force $(\mathrm{kg})$ necessary to incite a response. Using a previously described technique (Haussler, Behre \& Hill, 2008), the dynamometer was applied with a constant increase in pressure at a $90^{\circ}$ angle in relation to the contact surface. Pressure algometry was performed on each hoof at 10 different sites at the following locations: coronary band (medial, lateral, dorsal regions), heel bulbs (medial and lateral), sole (dorsal, palmaromedial, and palmarolateral regions), and dorsal lamellae (2 $\mathrm{cm}$ and $4 \mathrm{~cm}$ distal to the coronary band). All limbs are loaded during assessements, with exception of the sole sites. A $7 \mathrm{~mm}$ diameter flat tip 
113 was used for testing of the coronary band and heel bulbs, whereas a cone tip was used to evaluate

114 the dorsal lamellae and sole regions (Paz et al., 2016).

115

116

To avoid environmental distractions and visual perception of the algometer being applied,

117 a blindfold was applied over the eyes of each horse during each evaluation. The basal MNT for

118 each foot was determined prior to IA administration of each treatment. The minimum force

119 required to stimulate withdrawal of the limb was recorded (Zarucco et al., 2010). Sites were

120 assessed at 13 pre-selected times, beginning 10 min pre-injection (baseline), followed by 5,10 ,

$12115,20,30,60,90,120,150,180,210$, and $240 \mathrm{~min}$ post-injection. To avoid trauma to the horse's

122 foot, a maximum force of $6 \mathrm{~kg}$ was set to determine responsiveness based on previously studies,

123 which showed that horses did not react when forces over this value were applied (Zarucco et al.,

124 2010; Paz et al., 2016).

125

126

Preparation of the injectate was performed by an individual not blinded to the treatments.

127 Joint injections and dynamometer measurements were performed by a single investigator blinded

128 to the randomized treatments. Two additional evaluators, also blinded to the treatments

129 administered, evaluated the horses response to the applied instrument pressure. The response was

130 determined twice at each time in intervals of $2-4$ seconds, and the average of the two readings

131 was obtained. When divergence in a reading occurred between the evaluators, the value was

132 disregarded and the procedure repeated. After the experimental period, all horses received

133 phenylbutazone (4.4 $\mathrm{mg} \mathrm{kg}^{-1}$; Ourofino) IV daily for 5 days.

134

135 Statistical methods 
137 Wilk and Kolmogorov-Smirnov tests and determined to be not normally distributed. Therefore,

138 the data were tested non-parametrically using the Friedman test. Post hoc comparisons were

139 made using Dunn's test for comparison between times within each group and the Wilcoxon

140 signed-rank test for comparison between groups within each time. For all analyses, $P<0.05$ was

141 considered significant.

\section{Results}

The MNT for each location tested are represented in Fig (2-5). The results for the 150, 180,210 , and 240 min post-injection readings were nearly identical to the 120 min post-injection reading; therefore, only the 120 min value is represented graphically. There were no statistical differences $(P<0.05)$ over time or between treatment groups $(2 \%$ lidocaine and lactated ringer solution) for any of the variables analyzed (Table 1). However, signs of analgesia (MNT $\geq 3 \mathrm{~kg}$ ) were observed at various times in the dorsal lamellar region in 3/6 (50\%) of the horses studied (Fig. 2). In horse 1, the maximum force $(6 \mathrm{~kg})$ was applied $60 \mathrm{~min}$ post-injection in the lamellar region $4 \mathrm{~cm}$ distal the coronary band (Fig. 2). Horse 5 had MNT values $\geq 3 \mathrm{~kg}$ in the lamellar region $2 \mathrm{~cm}$ distal the coronary band at $15 \min (4.60 \mathrm{~kg}), 20 \mathrm{~min}(3 \mathrm{~kg})$, and $30 \mathrm{~min}(3 \mathrm{~kg})$ and 4 $\mathrm{cm}$ distal to the coronary band at $15 \min (4.80 \mathrm{~kg}), 20 \mathrm{~min}(6 \mathrm{~kg})$, and $30 \mathrm{~min}(6 \mathrm{~kg})$. Horse 6 had an MNT $\geq 3 \mathrm{~kg}$ in the lamellar region $2 \mathrm{~cm}$ distal the coronary band at $20 \mathrm{~min}(6 \mathrm{~kg}), 30 \mathrm{~min}$ $(5.85 \mathrm{~kg})$, and $60 \mathrm{~min}(5.36 \mathrm{~kg})$ and $4 \mathrm{~cm}$ distal to the coronary band at $20 \mathrm{~min}(3.65 \mathrm{~kg}), 30 \mathrm{~min}$

157 palmaromedial region of the sole, tolerating $6 \mathrm{~kg}$ at $60 \mathrm{~min}$ post-injection. 
159

160

161

162

163

164

165

166

167

168

169

170

171

172

173

174

175

176

177

178

179

180

181

\section{Discussion}

This study demonstrates that IA injection of the DIPJ with $5 \mathrm{~mL}$ of lidocaine does not result in statistical increases $(P<0.05)$ in MNT within the dorsal lamellae, sole, coronary band, or heel bulbs. However, 3/6 horses in this study demonstrated partial desensitization in the dorsal lamellar region between 15 and 60 min post-injection. These results suggest that diffusion of lidocaine from the DIPJ to the innervation of the dorsal lamellae should be considered when interpreting the effects of a DIPJ block. For diagnostic purposes, it is recommended to use the minimum anesthetic volume necessary for effective desensitization (Schumacher \& Schramme, 2018). Moyer, Schumacher \& Schumacher (2011) advocates using a volume of 4 to $6 \mathrm{~mL}$ for anesthesia of the DIPJ. Dyson (1998) suggests that the volume administered should not exceed 6 $\mathrm{mL}$, to avoid distention of the joint and leaking of the local anesthetic. Excessive distention of the joint with an anesthetic agent may promote subcutaneous extravasation at the injection site, increased diffusion, and desensitization of unintended structures (Schumacher \& Schramme, 2018). Consequently, low volumes of anesthetics may improve the specificity of DIPJ blocks;

therefore, low volumes were used in this study. Despite using a low volume $(5 \mathrm{~mL})$ of lidocaine, $50 \%$ of horses in this study demonstrated desensitization of the dorsal lamellae. Desensitization of the dorsal lamellae via perineural block of the palmar digital nerve (PDN) has been reported by Paz et al. (2016), determining that this region is innervated mainly by the medial and lateral PDNs. However, the possibility of the dorsal nerve branches contributing to dorsal lamellar tissue innervation in some horses was suggested in that study. Findings from our study suggest that, even with low volumes of lidocaine, injection into the DIPJ can result in anesthesia of the PDNs and/or their dorsal branches in some horses. 
183 lidocaine into the DIPJ, there was no statistical difference between treatment groups. This could

184 be explained by the variability in MNT responses in addition to a small sample size. Variability

185 in MNT responses between individuals has been observed when evaluating back pain in horses

186 (Haussler \& Erb, 2006). However, pressure algometry has been used reliably to identify and

187 quantify MNT within the equine digit, particularly for evaluation of coronary band (Zarucco et

188 al., 2010), heel bulbs (Jordana et al., 2014), dorsal lamellar region, and sole (Paz et al., 2016)

189 desensitization after local anesthestic administration. Furthermore, each horse was evaluated

190 prior to enrollment in the study to minimize variability. Horses were not enrolled into the study if

191 scarring of the distal limbs was noted or if they exhibited MNT responses $>1 \mathrm{~kg}$ of force.

192 Different from that, previous studies have reported MNT over $1 \mathrm{~kg}$ of force in clinically normal

193 horses (Haussler \& Erb, 2006). Many factors may have contributed to such divergences like

194 breed, level of horsemanship, part of the body, hair coat, and rate of pressure application of the 195 probe, but the major cause seems to be the probe configuration (Taylor et al, 2015). Haussler \&

196 Erb (2006) used a probe cover with rubber. Metallic probes were preferred for the current hoof 197 model based on conclusions from Taylor et al. (2015) that smaller probe tips may be preferable 198 as MNT data are less variable. In fact, baseline values registered in both groups were similar 199 from those previously reported using metallic probes with flat and conical tips (Taylor et al, 200 2015). Three of the six horses had MNTs of $3 \mathrm{~kg}$ and $6 \mathrm{~kg}$, occurring between 15 and $60 \mathrm{~min}$ 201 post-injection of lidocaine. Anesthesia of the dorsal lamellae could be explained by either 202 inadvertent infiltration of the subcutaneous tissues with lidocaine during IA injection or by 203 diffusion of lidocaine from the DIPJ to other tissues. However, the explanation that diffusion 204 occurred seems more likely, as MNT values $\geq 3 \mathrm{~kg}$ occurred after $15 \mathrm{~min}$. Previous studies have 
205 reported that anesthetic diffusion to the palmar structures of the foot occurred at a similar time

206 post-injection, determined by improvement of lameness associated with the podotrochlear

207 apparatus after infusion of $5 \mathrm{ml}$ of lidocaine into the DIPJ (Dau et al., 2017). Additionally, MNT

208 values were $<1.5 \mathrm{~kg}$ in the coronary band region at all evaluation times, suggesting that

209 inadvertent infiltration of the subcutaneous tissues was not the source of the anesthetic effect at

210 the dorsal lamellae. It is suspected that, despite the use of a low injection volume, diffusion of

211 lidocaine from the joint occurred resulting in desensitization of the dorsal lamellar region via the

212 dorsal branches of the PDNs. However, there is no evidence that the volume of anesthetic used

213 in the present study was sufficient to diffuse into the palmar regions of the foot to the extent

214 necessary for producing a complete perineural block of the PDNs. Previous studies have shown

215 that perineural anesthesia of this nerve in the distal portion promotes consistent desensitization of

216 the sole, heel bulbs, and dorsal lamellar tissue (Paz et al., 2016). Desensitization of the sole and

217 heel bulbs did not occur in the present study. Therefore, if only the dorsal branches and lamellar

218 terminations of the PDNs were desensitized by a low volume DIPJ block, an inconsistent MNT

219 response at the dorsal lamellae may occur (Paz et al., 2016).

The solar region of the hoof can become desensitized following administration of an anesthetic agent into the DIPJ (Schumacher et al., 2000; Schumacher et al., 2001; Sardari,

223 Kazemi \& Mohri, 2002). Using an experimental model to induce lameness via sole pressure,

224 horses were successfully desensitized in both the dorsal and palmar regions of the sole following injection of $10 \mathrm{~mL}$ of mepivacaine into the DIPJ (Schumacher et al., 2000). However, the use of a smaller injection volume $(6 \mathrm{~mL})$ promoted desensitization only in the dorsal region of the sole

227 (Schumacher et al., 2001). In contrast, the present study using $5 \mathrm{~mL}$ of $2 \%$ lidocaine did not 
228 result in significant increases in MNT in any portion of the sole. The lack of significant

229 desensitization of the solar region, demonstrated by response to pressure algometry, in these

230 horses suggests that $5 \mathrm{~mL}$ of lidocaine is insufficient volume to cause diffusion to the branches

231 of the PDNs that innervate the solar regions of the foot. Low injection volumes may not be large

232 enough to result in overdistention of the palmar recess. For example, $3 \mathrm{~mL}$ of plastic polymer

233 was not sufficient to completely fill the palmar recess of this joint (Bowker, 1997). Therefore, in

234 the current study, it is unlikely that the DIPJ palmar pouch became overdistended by the

235 administration of $5 \mathrm{~mL}$ of lidocaine, decreasing the possibility of anesthetic diffusion to the

236 branches of the PDNs responsible for the innervation of the solar corium. In contrast to previous

237 reports, horses in this experiment were confined to stocks during evaluations and not walked

238 post-injection (Schumacher et al., 2000; 2001; Sardari, Kazemi \& Mohri, 2002). Gough,

239 Mayhew \& Munroe (2002) suggests that the injection volume and resulting pressure within a

240 synovial structure may affect the anesthetic diffusion rate into adjacent synovial structures.

241 Therefore, the absence of joint movement may have resulted in lower IA pressure and, when

242 combined with a low injection volume, made it difficult for lidocaine to diffuse into the

243 surrounding tissues.

We also need to highlight that lidocaine was used in the present study and that most of the previous assays studying DIJ anesthesia effects used mepivacaine, which could promote a

247 different effect under the current set up/design. Another limitation of this study is the small number of horses and the lack of normal distribuition of the data. Under such circuntances, data was analysed by nonparametric tests that has lower power than do standard tests. By line of 
250 reason, a larger sample could indicate statistical difference between groups considering the MNT

251 values of dorsal lamellae.

252

253 Conclusions

254 Our findings suggest that the dorsal lamellae should be considered as a possible source of 255 lameness pain following 2\% lidocaine anesthetic block of the DIPJ in some horses. This

256 information is potential relevant in face of increasing number of horses with subclinical signs of

257 endocrinopathic laminitis reported nowadays (Patterson-Kane, Karikoski \& McGowan, 2018).

258 Further study and clinical observations are needed to confirm that local anesthetic may diffuse

259 from the DIPJ affecting the invervation of the dorsal lamellar region.

260

261 Conflict of interest statement

262

None of the authors has any financial or personal relationships that could inappropriately

263 influence or bias the content of the paper.

264

265 Aknowledgements

266

We would like to thank Dr. Britta Leise and Dr. Lee Ann Fugler for reviewing the

267

manuscript and FAPEMIG, CNPq, CAPES, and the Office of the Dean for Research at

268

Universidade Federal de Minas Gerais (PRPq-UFMG) for the financial support.

\section{References}

271 Bowker, RM, Linder, K, Van Wulfen, KK, Sonea, IM. 1997. Anatomy of the distal

272 interphalangeal joint of the mature horse: relationships with navicular suspensory ligaments, 
273 sensory nerves and neurovascular bundle. Equine Veterinary Journal 29: 126-135 DOI:

274 10.1111/j.2042-3306.1997.tb01654.x.

275

276 Bowker, RM. 2007. Innervation of the equine foot: its importance to the horse and to the

277 clinician. In: Floyd A, Mansmann R, eds. Equine Podiatry.St Louis: Saunders Elsevier, 76-78.

278

279 Dau, SL, Azevedo, MS, De La Corte, FD, Brass, KE, Gallio, M, Ceni, F, Lubini, BB. 2017.

280 Response of three digital anesthetic technics in horses with forelimb hoof lameness. Arquivo

281 Brasileiro de Medicina Veterinária e Zootecnia 69: 793-801 DOI: 10.1590/1678-4162-9155.

282

283

284

Dyson, SJ, Kidd, L. 1993. General articles a comparison of responses to analgesia of the

navicular Bursa and intra-articular analgesia the distal interphalangeal joint in 59 horses. Equine

Veterinary Journal 25: 93-98 DOI: 10.1111/j.2042-3306.1993.tb02915.x.

286

287

Dyson, SJ. 1998. The puzzle of distal interphalangeal joint pain. Equine Veterinary Education 10: 119-125 DOI: 10.1111/j.2042-3292.1998.tb00862.x.

289

290

Dyson, SJ, Murray, RC, Schramme, M, Branch, M. 2003. Lameness in 46 horses associated with 291 deep digital flexor tendonitis in the digit: diagnosis using magnetic resonance imaging. Equine Veterinary Journal 35: 681-690 DOI: 10.2746/042516403775696294.

294 Easter, JE, Watkins, JP, Stephens, SL, Carter, GK, Hague, BA, Dutton, DW, Honnas, CM. 2000. 295 Effects of regional anesthesia on experimentally induced coffin joint synovitis. In: Proceedings 
296 of the Annual Convention American Association of Equine Practitioners, San Antonio, Texas,

297 USA, 26th-29th November, 214-216.

298

299 Gough, MR, Mayhew, IG, Munroe, GA. 2002. Diffusion of mepivacaine between adjacent

300 synovial structures in the horse. Part 1: forelimb foot and carpus. Equine Veterinary Journal 34:

301 80-84 DOI: 10.2746/042516402776181097.

302

303

304

Haussler, KK, Behre, TH, Hill, AE. 2008. Mechanical nociceptive thresholds within the pastern region of Tennessee Walking Horses. Equine Veterinary Journal 40: 455-459 DOI:

305 $10.2746 / 042516408 \times 278166$.

306

307

Haussler, KK, Erb, HN. 2006. Mechanical nociceptive thresholds in the axial skeleton of horses. 308 Equine Veterinary Journal 38: 70-75 DOI: 10.2746/042516406775374315.

309

Jordana, M, Martens, A, Duchateau, L, Vanderperren, K, Saunders, J, Oosterlinck, M, Pille, F.

2014. Distal limb desensitisation following analgesia of the digital flexor tendon sheath in horses using four different techniques. Equine Veterinary Journal 46: 488-493 DOI: 10.1111/evj.12186. 
317 Keegan, KG, Wilson, DA, Kreeger, JM, Ellersieck, MR, Kuo, KC, Li, Z. 1996. Local

318 distribution of mepivacaine after distal interphalangeal joint injection in horses. American

319 Journal of Veterinary Research 57: 422-426.

320

321 Moyer, W, Schumacher, J, Schumacher, J. 2011. In: Moyer, Schumacher \& Schumacher, eds.

322 Equine Joint Injection and Regional Anesthesia. Chadds Ford: Academic Veterinary Solutions, $323 \quad 12-19$.

324

325

Patterson-Kane, JC, Karikoski, NP, McGowan, CM. 2018. Paradigm shifts in understanding 326 equine laminitis. The Veterinary Journal 231: 33-40 DOI: 10.1016/j.tvj1.2017.11.011.

327

328

Paz, CFR, Magalhaes, JF, Mendes, HMF, Rocha Junior, SS, Belknap, JK, Alves, GES, Faleiros, 329 RR. 2016. Mechanical nociceptive thresholds of dorsal laminae in horses after local anaesthesia 330 of the palmar digital nerves or dorsal branches of the digital nerve. The Veterinary Journal 214 : 102-108 DOI: 10.1016/j.tvj1.2016.05.005.

332

333

Pleasant, RS, Moll, HD, Ley, WB, Lessard, P, Warnick, LD. 1997. Intraarticular anesthesia of the distal interphalangeal joint alleviates lameness associated with the navicular bursa in horses. 335 Veterinary Surgery 26: 137-140 DOI: 10.1111/j.1532-950x.1997.tb01476.x.

337 Sardari, K, Kazemi, H, Mohri, M. 2002. Effects of analgesia of the distal interphalangeal joint 338 and navicular bursa on experimental lameness caused by solar pain in horses. Journal of 
339 veterinary medicine. A, Physiology, pathology, clinical medicine 49: 478-481

340 DOI: 10.1046/j.1439-0442.2002.00482.x.

341

342 Schumacher, J, Steiger, R, Schumacher, J, De Graves, F, Schramme, M, Smith, R, Coker, M.

343 2000. Effects of analgesia of the distal interphalangeal joint or palmar digital nerves on lameness

344 caused by solar pain in horses. Veterinary Surgery 29: 54-58 DOI: $10.1111 / \mathrm{j} .1532-$

345 950x.2000.00054.x.

346

347 Schumacher, J, Schumacher, J, De Graves, F, Steiger, R, Schramme, M, Smith, R, Coker, M.

348 2001. A comparison of the effects of two volumes of local analgesic solution in the distal

349 interphalangeal joint of horses with lameness caused by solar toe or solar heel pain. Equine

350 Veterinary Journal 33: 265-268 DOI: 10.2746/042516401776249778.

351

352 Schumacher, J, Schramme, MC, Schumacher, J, De Graves FJ. 2013. Diagnostic analgesia of the 353 equine digit. Equine Veterinary Education 25: 408-421 DOI: 10.1111/eve.12001.

Schumacher, J, Schramme, M. 2018. Diagnostic and Regional Surgical Anesthesia of the limbs and axial skeleton In: Auer, Stick, Kummerle \& Prange, eds. Equine Surgery. St. Louis: saunders

357 Elsevier, 1220-1227.

Zarucco, L, Driessen, B, Scandella, M, Cozzi, F, Cantile, C. 2010. Sensory nerve conduction and nociception in the equine lower forelimb during perineural bupivacaine infusion along the palmar nerves. The Canadian Journal of Veterinary Research 74: 305-313. 


\section{Figure 1}

Equine hoof capsule images showing the points for mechanical nociceptive threshold assessment in the dorsal hoof wall and sole.

(A) Defects created in the dorsal hoof wall, 2 and 4 centimeters away from the coronary band. (B) Defects created at dorsal (1), palmaromedial (2) and palmarolateral (3) borders of sole. Note that horn was removed in order to reach the flexible portion of the cornified tissue, but without causing exposure or injury of the underneath corium.
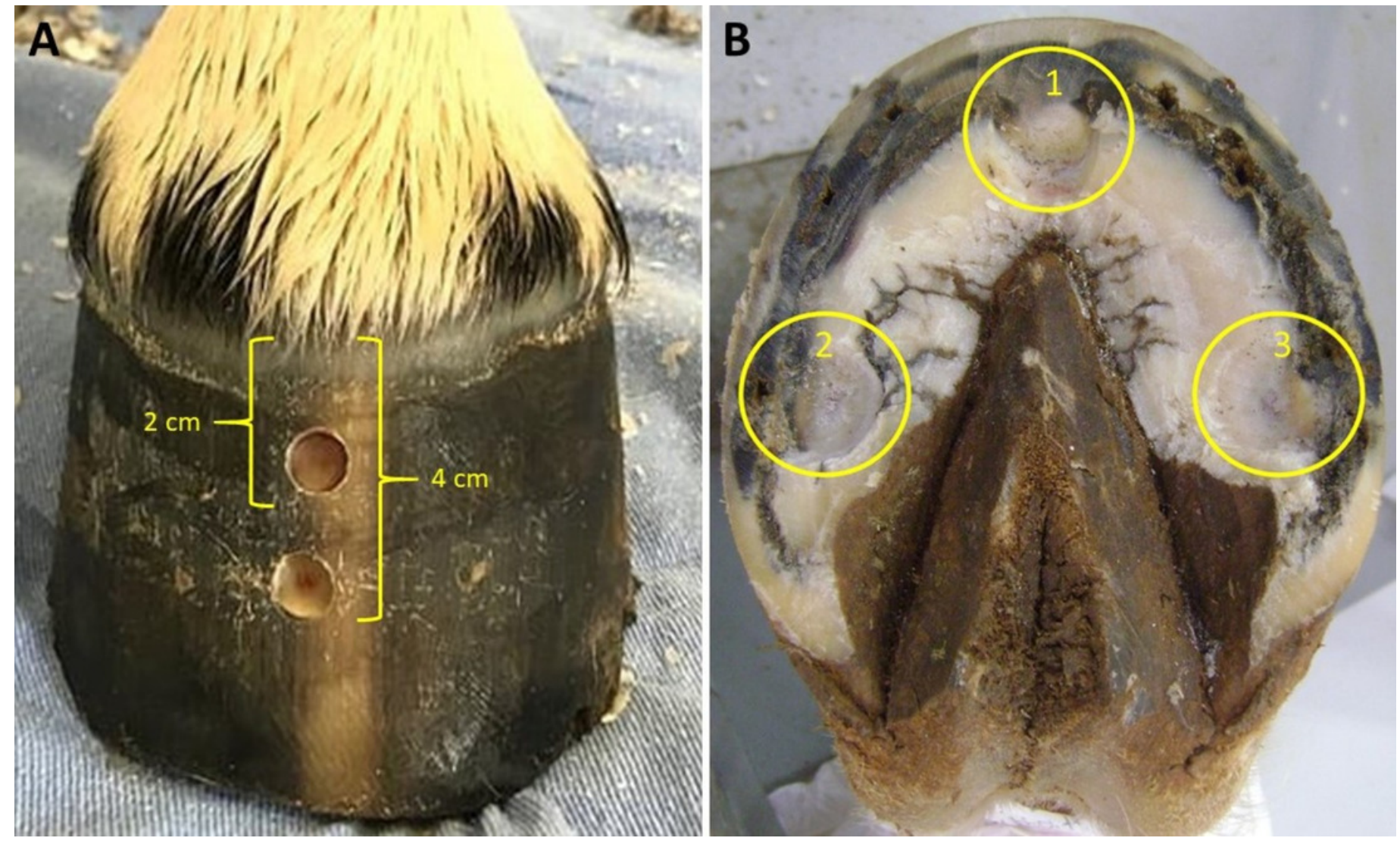
Figure 2

Graphical representation of mechanical nociceptive threshold values.

Evaluation of dorsal lamella regions (LAM $2 \mathrm{~cm}$ ) and $($ LAM $4 \mathrm{~cm}$ ) distal to coronary band of hooves in healthy equine limbs, injected into distal interphalangeal joint with lactated ringers solution or $2 \%$ lidocaine. Each marker represent a single horse, median expressed in lines. 
LAM $2 \mathrm{~cm}$

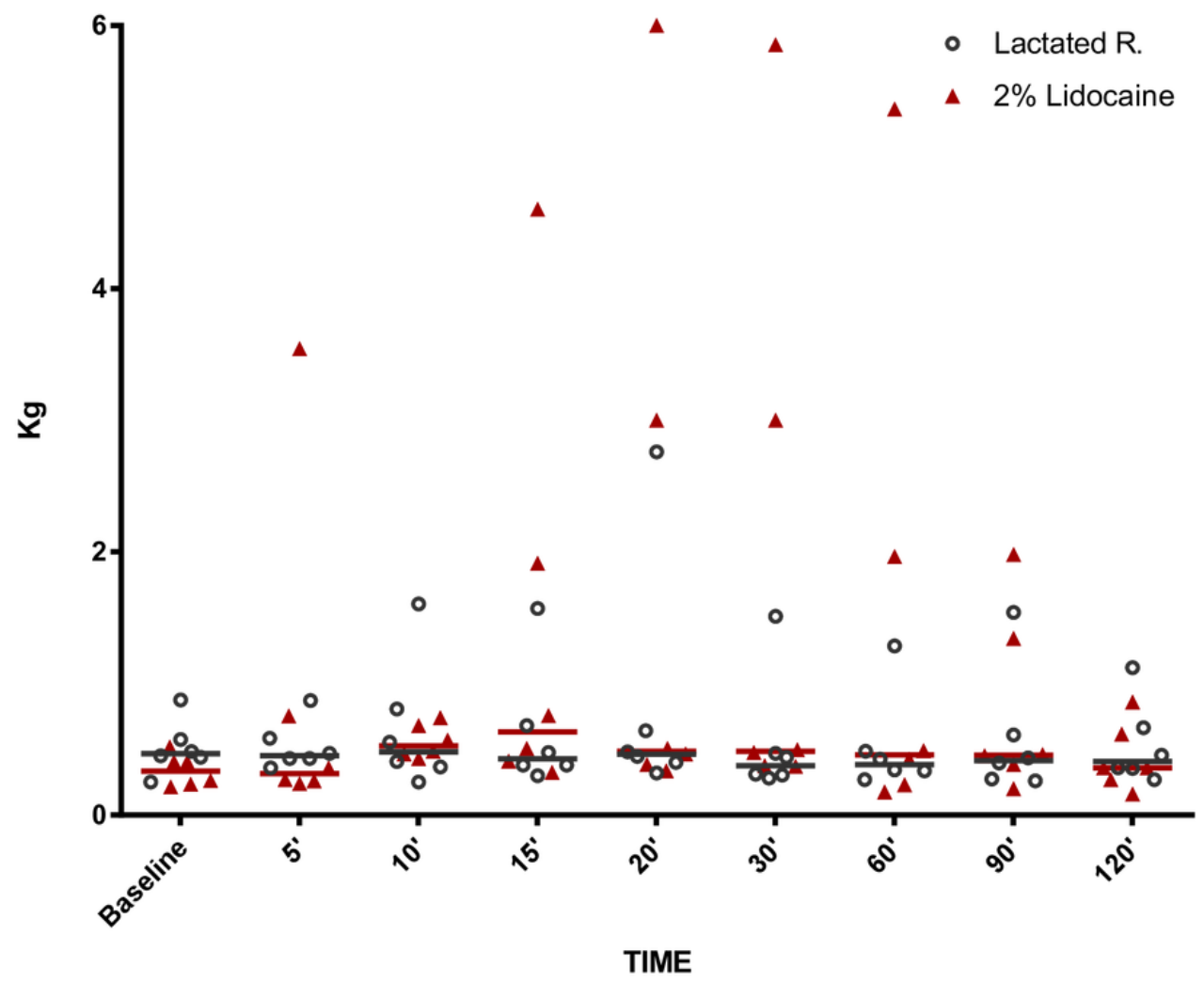

LAM $4 \mathrm{~cm}$

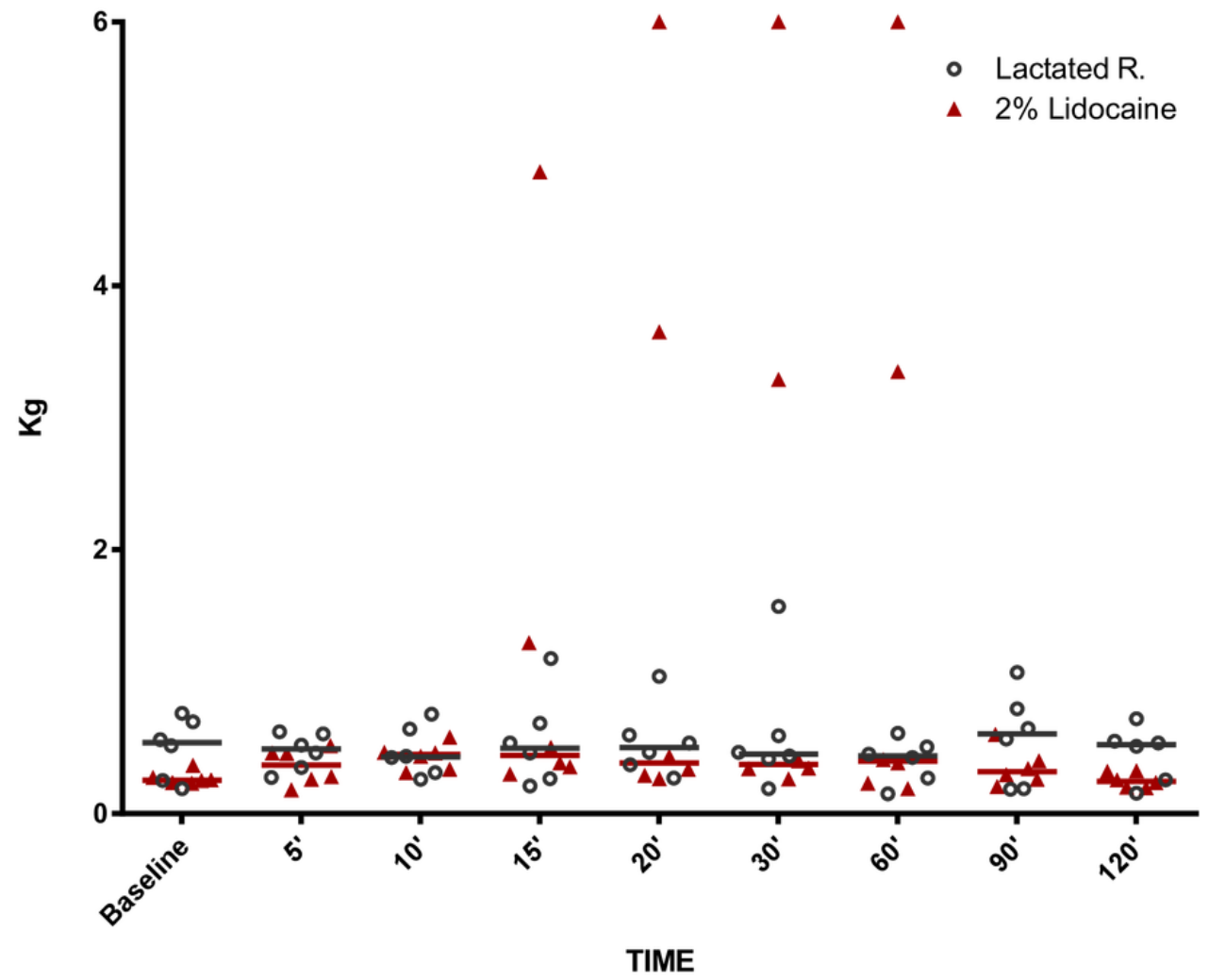


Figure 3

Graphical representation of mechanical nociceptive threshold values.

Evaluation of heel bulbs (medial and lateral) in healthy equine limbs, injected into distal interphalangeal joint with lactated ringers solution or $2 \%$ lidocaine. Each marker represent a single horse, median expressed in lines. 


\section{Medial Heel Bulbs}

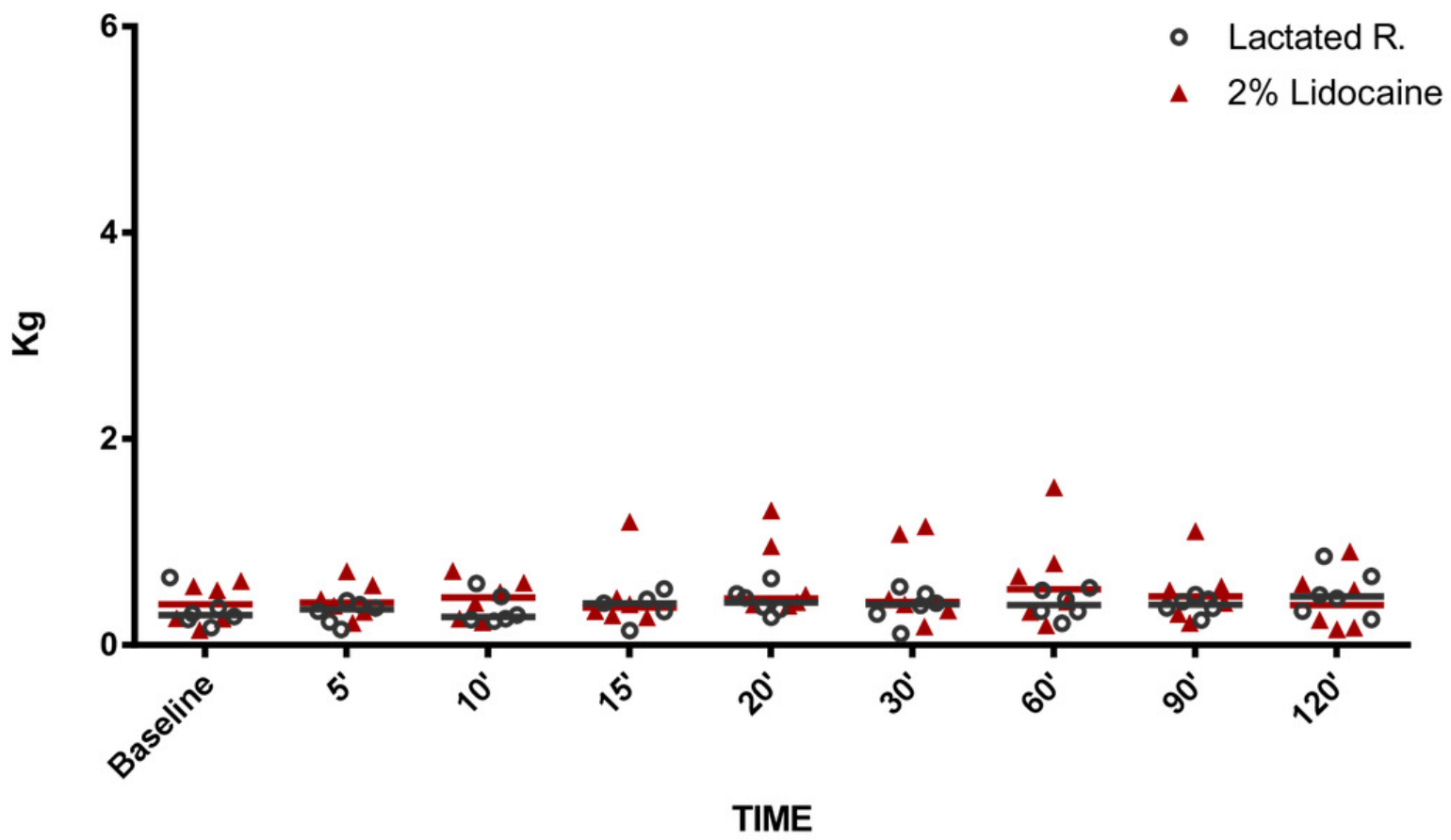

\section{Lateral Heel Bulbs}

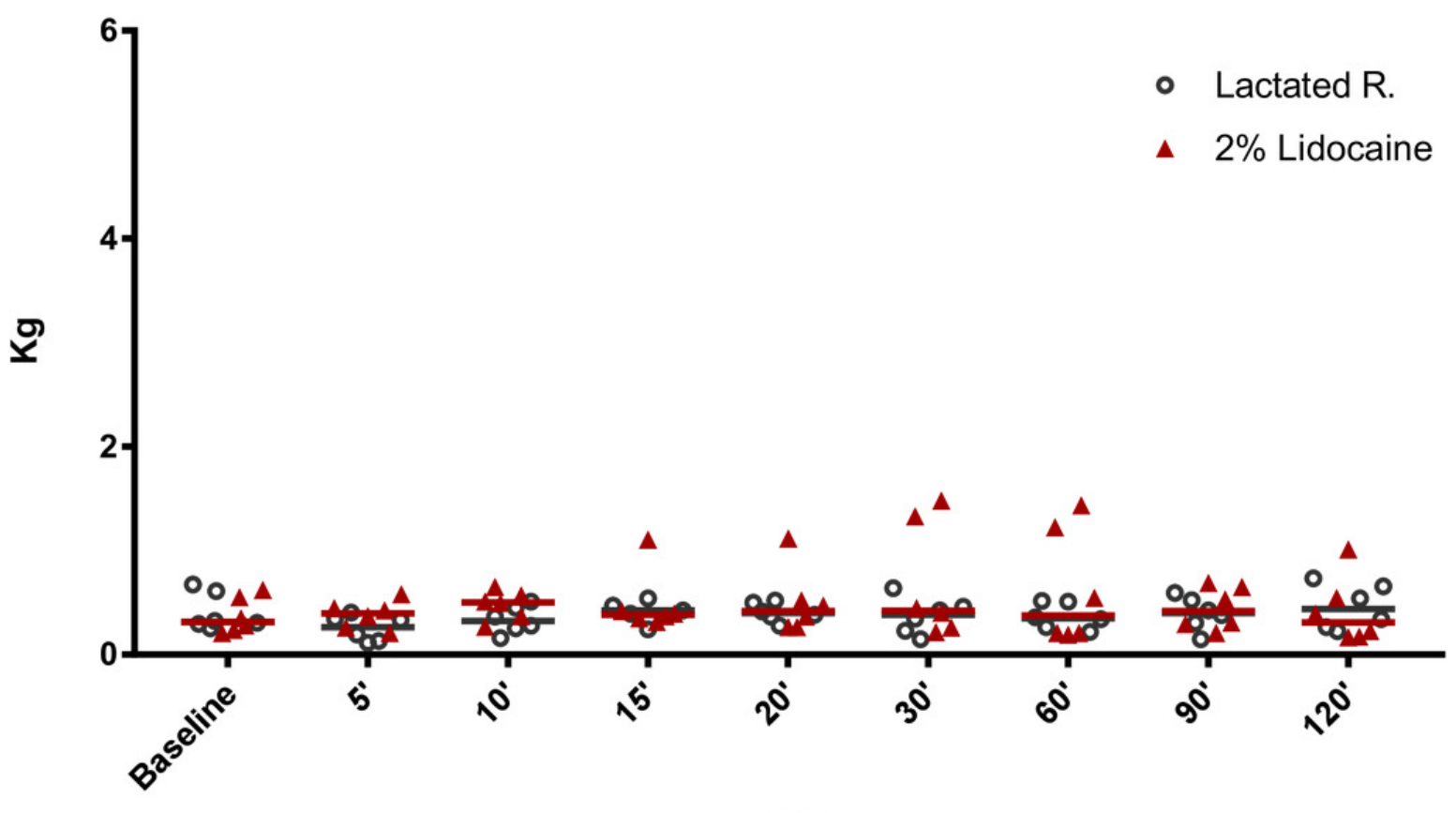

TIME 


\section{Figure 4}

Graphical representation of mechanical nociceptive threshold values.

Evaluation of coronary band (lateral, dorsal and medial) in healthy equine limbs, injected into distal interphalangeal joint with lactated ringers solution or $2 \%$ lidocaine. Each marker represent a single horse, median expressed in lines. 

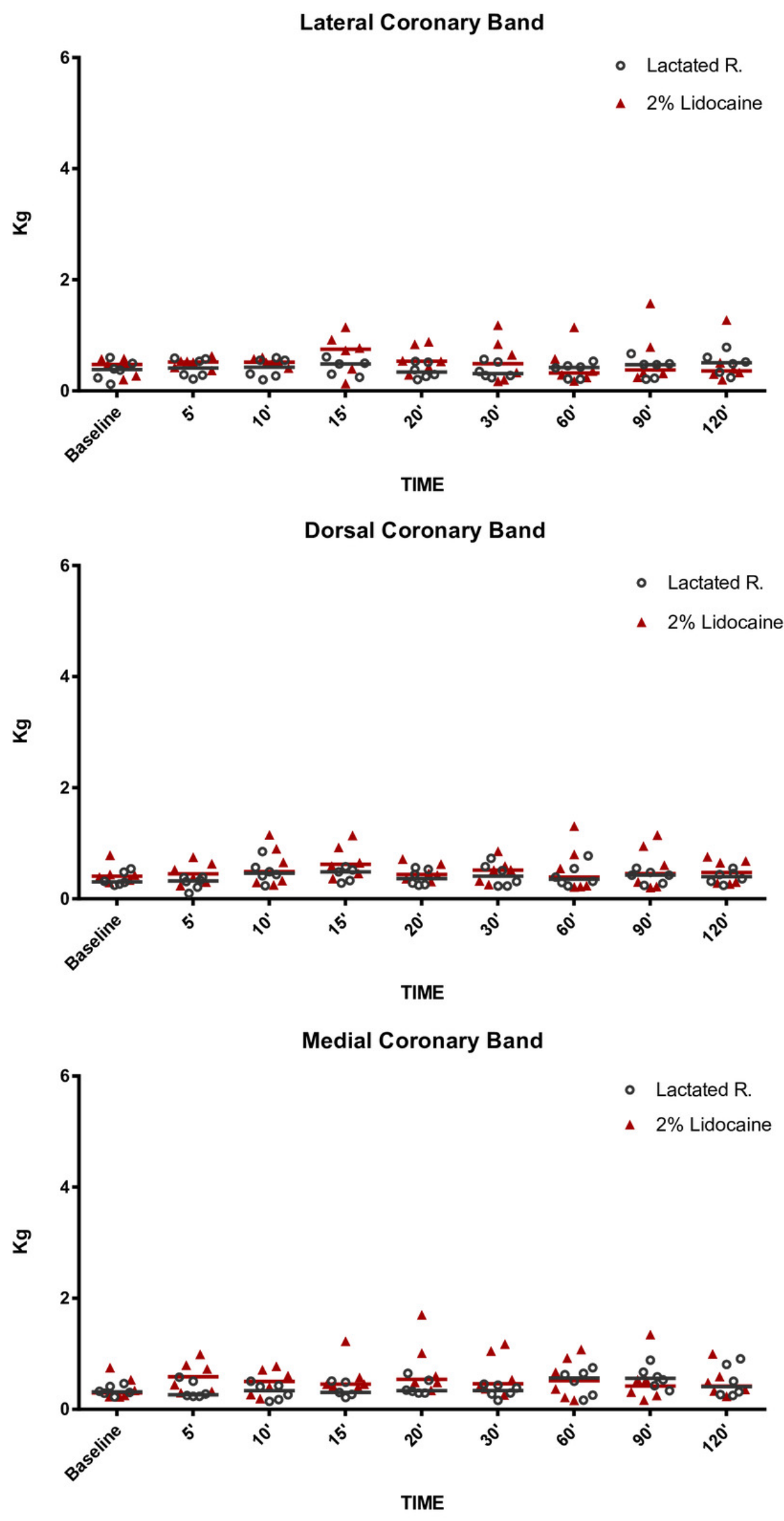


\section{Figure 5}

Graphical representation of mechanical nociceptive threshold values.

Evaluation of sole borders (dorsal, palmaromedial and palmarolateral) in healthy equine limbs, injected into distal interphalangeal joint with lactated ringers solution or $2 \%$ lidocaine. Each marker represent a single horse, median expressed in lines. 

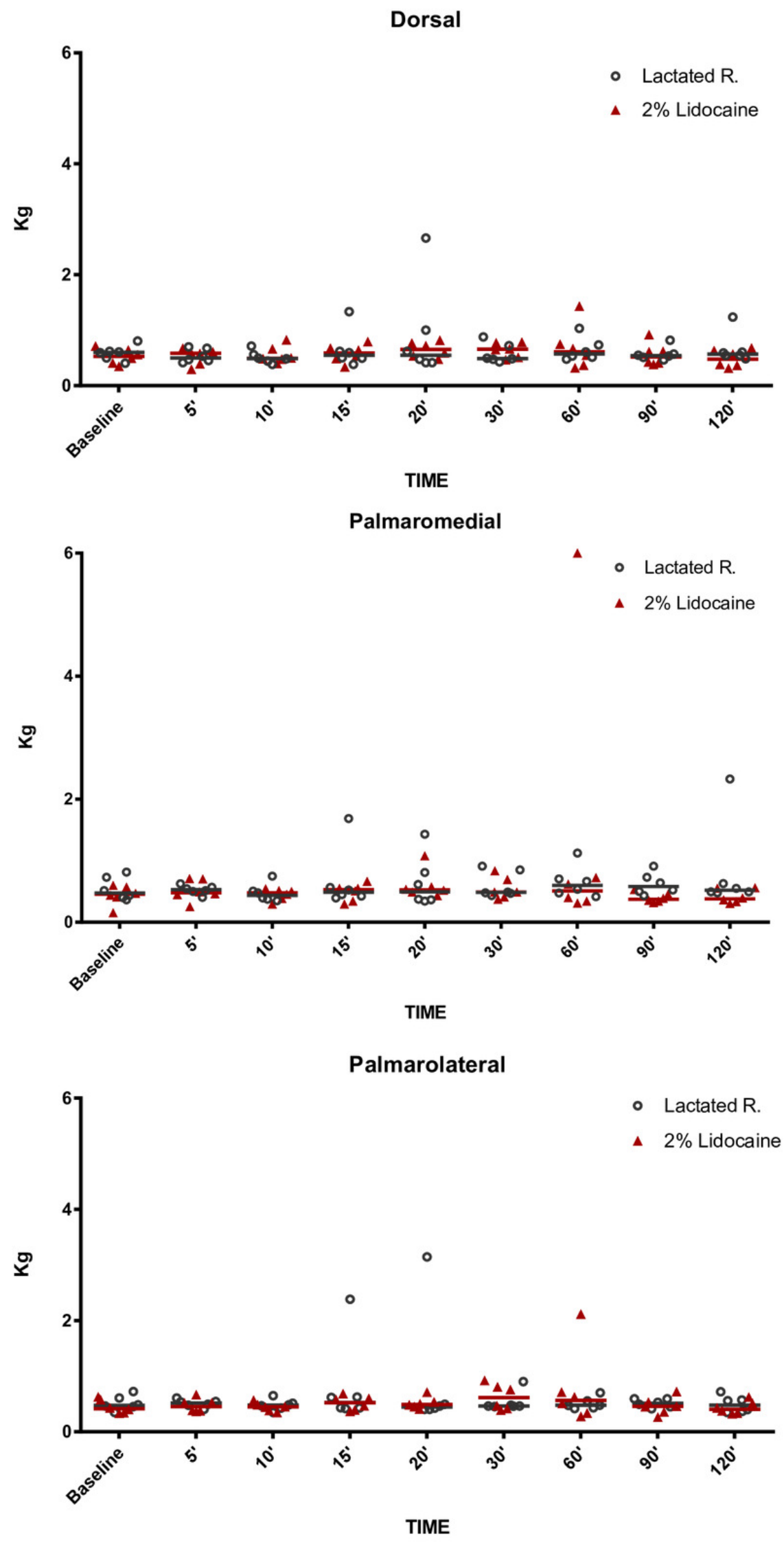


\section{Table $\mathbf{1}$ (on next page)}

Means (range) mechanical nociceptive thresholds.

Means (range) mechanical nociceptive thresholds (in $\mathrm{kg}$ ) obtained from the dorsal lamella (LAM, 2 and $4 \mathrm{~cm}$ distal to the coronary band), sole, bulbs of the heel and coronary band of the forelimb hooves inhorses subjected to distal interphalangeal joint infiltration with $5 \mathrm{~mL}$ of lidocaine $2 \%$ (L) or Ringer's lactated solution (RS). 
1

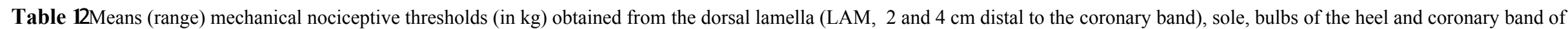
the forel $3 \mathrm{mb}$ hooves in horses subjected to distal interphalangeal joint infiltration with $5 \mathrm{~mL}$ of lidocaine $2 \%$ (L) or Ringer's lactated solution (RS).

\begin{tabular}{|c|c|c|c|c|c|c|c|c|c|}
\hline \multirow[b]{2}{*}{ atment-Region } & \multicolumn{9}{|c|}{ Minutes } \\
\hline & Baseline & $5^{\prime}$ & $10^{\prime}$ & $15^{\prime}$ & $20^{\prime}$ & $30^{\prime}$ & $60^{\prime}$ & $90^{\prime}$ & $120^{\prime}$ \\
\hline LAM $2 \mathrm{~cm}$ & $0.51(0.25-0.87)$ & $0.52(0.36-0.87)$ & $0.66(0.25-1.60)$ & $0.63(0.30-1.57)$ & $0.84(0.32-2.76)$ & $0.55(0.28-1.51)$ & $0.52(0.27-1.28)$ & $0.58(0.26-1.54)$ & $0.53(0.27-1$ \\
\hline $\mathrm{AM} 2 \mathrm{~cm}$ & $0.34(0.21-0.51)$ & $0.90(0.24-2.54)$ & $0.56(0.43-0.74)$ & $1.41(0.32-4.60)$ & $1.78(0.33-3.75)$ & $1.76(0.37-5.85)$ & $1.44(0.17-5.36)$ & $0.80(0.2-1.98)$ & $0.49(0.14-1$ \\
\hline $\mathrm{LAM} 4 \mathrm{~cm}$ & $0.49(0.19-0.76)$ & $0.47(0.27-0.62)$ & $0.47(0.26-0.75)$ & $0.55(0.21-1.17)$ & $0.54(0.27-1.04)$ & $0.61(0.19-1.57)$ & $0.40(0.15-0.61)$ & $0.57(0.18-1.07)$ & $0.45(0.15-0$ \\
\hline $\mathrm{AM} 4 \mathrm{~cm}$ & $0.26(0.23-0.36)$ & $0.35(0.18-0.51)$ & $0.43(0.31-0.58)$ & $1.28(0.30-4.86)$ & $1.82(0.26-6.00)$ & $1.77(0.26-6.00)$ & $1.76(0.19-6.00)$ & $0.35(0.20-0.60)$ & $0.25(0.19-0$ \\
\hline Sole (Dorsal) & $0.58(0.40-0.80)$ & $0.54(0.41-0.70)$ & $0.51(0.38-0.71)$ & $0.65(0.38-1.33)$ & $0.93(0.41-2.66)$ & $0.58(0.43-0.88)$ & $0.65(0.48-1.03)$ & $0.57(0.46-0.82)$ & $0.66(0.48-1$ \\
\hline ole (Dorsal) & $0.52(0.35-0.71)$ & $0.52(0.29-0.67)$ & $0.55(0.40-0.82)$ & $0.57(0.34-0.79)$ & $0.65(0.48-0.82)$ & $0.64(0.47-0.78)$ & $0.68(0.32-1.43)$ & $0.56(0.38-0.92)$ & $0.49(0.31-0$ \\
\hline -Sole (Palmaromedial) & $0.54(0.36-0.81)$ & $0.52(0.40-0.62)$ & $0.47(0.35-0.75)$ & $0.67(0.39-1.68)$ & $0.65(0.34-1.43)$ & $0.60(0.43-0.91)$ & $0.65(0.41-1.25)$ & $0.62(0.43-0.91)$ & $0.83(0.48-2$ \\
\hline le (Palmaromedial) & $0.44(0.15-0.60)$ & $0.51(0.25-0.71)$ & $0.44(0.29-0.54)$ & $0.48(0.29-0.66)$ & $0.60(0.43-1.08)$ & $0.54(0.37-0.83)$ & $1.40(0.31-6.00)$ & $0.39(0.32-0.53)$ & $0.41(0.30-0$ \\
\hline Sole (Palmarolateral) & $0.51(0.35-0.72)$ & $0.51(0.40-0.61)$ & $0.48(0.35-0.65)$ & $0.81(0.42-2.38)$ & $0.89(0.40-3.14)$ & $0.53(0.45-0.90)$ & $0.51(0.42-0.70)$ & $0.51(0.41-0.59)$ & $0.49(0.35-0$ \\
\hline le (Palmarolateral) & $0.45(0.33-0.63)$ & $0.47(0.37-0.67)$ & $0.44(0.35-0.57)$ & $0.51(0.37-0.68)$ & $0.51(0.41-0.71)$ & $0.62(0.39-0.92)$ & $0.76(0.28-2.11)$ & $0.46(0.26-0.72)$ & $0.43(0.32-0$ \\
\hline Bulbs (Lateral) & $0.41(0.25-0.67)$ & $0.25(0.11-0.25)$ & $0.33(0.16-0.51)$ & $0.41(0.24-0.54)$ & $0.41(0.28-0.52)$ & $0.37(0.15-0.64)$ & $0.36(0.22-0.51)$ & $0.39(0.15-0.59)$ & $0.46(0.22-0$ \\
\hline ulbs (Lateral) & $0.37(0.21-0.62)$ & $0.38(0.21-0.58)$ & $0.47(0.26-0.65)$ & $0.49(0.31-1.10)$ & $0.50(0.26-1.11)$ & $0.68(0.21-1.48)$ & $0.63(0.19-1.43)$ & $0.44(0.21-0.69)$ & $0.41(0.16-1$ \\
\hline Bulbs (Medial) & $0.33(0.17-0.65)$ & $0.31(0.15-0.43)$ & $0.34(0.23-0.59)$ & $0.37(0.14-0.54)$ & $0.43(0.27-0.64)$ & $0.37(0.11-0.56)$ & $0.39(0.21-0.55)$ & $0.38(0.24-0.49)$ & $0.50(0.25-0$ \\
\hline ulbs (Medial) & $0.39(0.14-0.62)$ & $0.44(0.21-0.71)$ & $0.45(0.22-0.71)$ & $0.48(0.27-1.19)$ & $0.65(0.38-1.30)$ & $0.59(0.18-1.15)$ & $0.65(0.19-1.53)$ & $0.52(0.21-1.10)$ & $0.43(0.15-0$ \\
\hline Coronary band (Lateral) & $0.36(0.12-0.60)$ & $0.41(0.21-0.59)$ & $0.41(0.20-0.59)$ & $0.42(0.24-0.61)$ & $0.36(0.20-0.53)$ & $0.37(0.23-0.57)$ & $0.37(0.21-0.53)$ & $0.42(0.21-0.67)$ & $0.49(0.24-0$ \\
\hline oronary band (Lateral) & $0.42(0.20-0.58)$ & $0.49(0.36-0.62)$ & $0.52(0.41-0.60)$ & $0.68(0.13-1.14)$ & $0.58(0.29-0.88)$ & $0.56(0.17-1.18)$ & $0.46(0.17-1.14)$ & $0.61(0.24-1.57)$ & $0.50(0.2$ \\
\hline Coronary band (Medial) & $0.33(0.22-0.46)$ & $0.34(0.23-0.58)$ & $0.32(0.14-0.50)$ & $0.35(0.21-0.51)$ & $0.40(0.29-0.65)$ & $0.33(0.16-0.45)$ & $0.49(0.16-0.75)$ & $0.57(0.33-0.88)$ & $0.50(0.25-0$ \\
\hline oronary band (Medial) & $0.38(0.22-0.75)$ & $0.59(0.29-0.99)$ & $0.49(0.19-0.77)$ & $0.58(0.39-1.22)$ & $0.76(0.34-1.70)$ & $0.62(0.25-1.17)$ & $0.56(0.16-1.07)$ & $0.52(0.16-1.34)$ & $0.49(0.23-0$ \\
\hline oronary band (Dorsal) & $0.35(0.24-0.54)$ & $0.28(0.10-0.39)$ & $0.49(0.23-0.85)$ & $0.44(0.28-0.58)$ & $0.38(0.24-0.56)$ & $0.43(0.23-0.73)$ & $0.42(0.23-0.77)$ & $0.39(0.24-0.55)$ & $0.39(0.24-0$ \\
\hline ronary band (Dorsal) & $0.44(0.29-0.78)$ & $0.46(0.23-0.75)$ & $0.59(0.25-1.15)$ & $0.68(0.36-1.14)$ & $0.48(0.31-0.71)$ & $0.50(0.25-0.85)$ & $0.55(0.21-1.30)$ & $0.57(0.20-1.14)$ & $0.48(0.26-0$ \\
\hline
\end{tabular}


